\title{
Preface
}

\section{Understanding of nicotinic acetylcholine receptors}

\author{
Jie $\mathrm{WU}^{*}$ \\ Barrow Neurological Institute, St Joseph's Hospital and Medical Center, Phoenix, AZ 85013, USA
}

Acta Pharmacologica Sinica (2009) 30: 653-655; doi: 10.1038/aps.2009.89

Cigarette smoking is a major public health problem and has been identified as the second-most prevalent cause of death in the world. China, a country with a population of 1.3 billion, is the world's largest producer and consumer of tobacco. It estimates that there are 0.35 billion cigarette smokers in China, which bears a large proportion of the deaths attributable to smoking worldwide ${ }^{[1]}$. Cigarette smoking results in more than 1000000 premature deaths each year in China - about 1 in every 5 premature deaths ${ }^{[2]}$. Economically, more than $\$ 166$ billion per year of total Chinese healthcare costs are attributable directly to smokingassociated diseases. If the costs of lost productivity due to smoking are added (estimated at $\$ 86$ billion per year), the economic burden of smoking is more than $\$ 252$ billion per year, in China alone. Recent estimates indicate that approximately one-quarter of the world's population smokes, that smoking is currently responsible for 1 in every 10 premature deaths worldwide (about 5 million deaths each year) ${ }^{[3]}$, and that this number will double by 2025 unless effective action is taken. Thus, there is an urgent need to reduce smoking prevalence worldwide. Unfortunately, nicotine dependence severely confounds attempts to end tobacco product use.

Nicotine is the major biologically active substance that promotes the use of tobacco products. Nicotine exerts its biological effects through nicotinic acetylcholine receptors (nAChRs). nAChRs are prototypical members of the ligandgated ion channel superfamily of neurotransmitter receptors ${ }^{[4]}$. nAChRs represent both classic and contemporary models for the establishment of concepts pertaining to mechanisms of

\footnotetext{
* Correspondence to Jie WU, MD, PhD. Senior Staff Scientist, Director of Neural Physiology Laboratory, Barrow Neurological Institute, St Joseph's Hospital and Medical Center, 350 West Thomas Road, Phoenix, AZ 85013.

E-mail jie.wu@chw.edu

Received 2009-04-20 Accepted 2009-04-27
}

drug action, synaptic transmission, and structural/functional diversity of transmembrane signaling molecules ${ }^{[4]}$. Neuronal nAChRs are found throughout the central nervous system and exist as multiple, diverse subtypes of pentameric structures with unique combinations from at least twelve ( $\alpha 2-\alpha 10$, $\beta 2-\beta 4)$ genetically-distinct subunits ${ }^{[5]}$. Binding by endogenous (acetylcholine) or exogenous (nicotine) agonists to $\mathrm{nAChR}$ opens an intrinsic ion channel in the receptor, allowing the flow of cation ions $\left(\mathrm{Na}^{+}, \mathrm{Ca}^{2+}\right.$, and $\left.\mathrm{K}^{+}\right)$through the cell membrane, and inducing a wide variety of biological responses. Accumulating lines of evidence demonstrate that $\mathrm{nAChRs}$ play critical roles in mediating nicotine reward, dependence and addiction ${ }^{[6,7]}$. In addition, alterations of nAChRs have been found in various diseases such as Parkinson's diseases, Alzheimer's disease, schizophrenia, depression, epilepsy, diabetes, respiration disorders and some immunological disorders ${ }^{[8]}$. Therefore, understanding the molecular biology, physiology, pharmacology and pathophysiology of neuronal nAChRs will significantly improve the diagnosis, prevention and treatment of these diseases and pathological conditions, including nicotine addiction.

Until recently, much of our understanding of the physiology and pharmacology of neuronal nAChRs has come from heterologous expression studies. Principally using Xenopus oocytes as hosts, but also using transfected mammalian cells, these efforts have helped to define the realm of possibilities for $\mathrm{nAChR}$ subunit combinations that can form functional channels ${ }^{[9]}$. A variety of experimental approaches have been employed in the study of natively-expressed nAChRs, including molecular and cellular biology, electrophysiology, neurotransmitter release analyses, isotopic ion flux studies, immunochemistry, neuroanatomy, calcium imaging and behavioral testing. Studies using transgenic mice have helped to identify subunits that constitute some native, functional nAChR subtypes. Recently, significant insights have been 
gained regarding the molecular, cellular and system basis of nAChR function in the brain. For instance, at the atomic and molecular level, X-ray crystallographic structures of acetylcholine binding proteins (AChBPs) are providing new answers to questions about how nAChRs function as biophysical machines, and as participants in cellular and systems physiology ${ }^{[10]}$. The studies of structure-function relationships have revealed that the structures of different $n A C h R s$ with different pharmacological profiles and kinetics will help to illustrate how agonists and antagonists bind to orthosteric binding sites, how allosteric modulators alter receptor function by binding outside these sites, how nAChRs gate ion flow, and how nAChR cytoplasmic domains affect receptor function $^{[4,11,12]}$. At the level of cellular and system biology, the functional subtypes of native nAChRs have been identified in different brain areas and their roles in the mediation of nicotine reward, dependence and addiction are beginning to be elucidated ${ }^{[5,13,14]}$ Particularly, nicotine-induced neuronal adaptations (nAChR up-regulation and synaptic plasticity) in the brain reward center (ventral tegmental area) have been postulated as an important cellular mechanism of nicotine reinforcement ${ }^{[15-17]}$. At the behavioral level, nicotine selfadministration experiments combined with $\mathrm{nAChR}$ subunit knockout mice have provided important evidence concerning which $\mathrm{nAChR}$ subtypes are crucial for nicotine seeking behavior ${ }^{[7,18,19]}$. Finally, based on the above experimental data, some theoretical models of nAChR-associated signal pathways and neuronal circuits have been proposed to interpret the roles of nAChRs in addiction, neurodegeneration, and mental illnes ${ }^{[20-22]}$.

Collectively, multiple findings indicate that nAChRs in the brain play roles not only in the mediation of classical, excitatory, cholinergic neurotransmission at selected loci, but also, and perhaps more globally, in the modulation of neurotransmission by other chemical messengers, including glutamate, GABA, the monoamines, including dopamine, norepinephrine and serotonin, and acetylcholine $(\mathrm{ACh})$ itself. This means that some $\mathrm{nAChR}$ subtypes have postsynaptic (or peri-synaptic), somatodendritic localizations, whereas others have pre-synaptic dispositions. Moreover, some nAChRs have been implicated in processes such as structuring and maintenance of neurites and synapses. Thus, nAChRs may play complex and important roles in neuronal function and in neurological and psychological diseases.

In this nAChR-themed issue, I bring together many of world's leading researchers in the nAChR research field to provide state-of-the-art reviews, and original research articles, covering a wide range of nAChR-related areas. These articles span from molecular to behavioral investigations involving different experimental techniques such as molecular/cell biology, biophysics, electrophysiology, receptor pharmacology and behavioral testing. The articles in this specific issue provide a broad perspective on current advances in $\mathrm{nAChR}$ studies. I hope this issue will provide a foundation for future developments in $\mathrm{AChR}$ research. In particular, I sincerely hope that this specific issue will promote the further engagement of Chinese scientists in nAChR-related research, smoking cessation efforts, and the management of smoking-associated diseases in China.

\section{References}

1 Wright AA, Katz IT. Tobacco tightrope - balancing disease prevention and economic development in China. N Engl J Med 2007; 356: 1493-6.

2 Gu D, Kelly TN, Wu X, Chen J, Samet JM, Huang JF, et al. Mortality attributable to smoking in China. N Engl J Med 2009; 360: 150-9.

3 Lopez AD, Mathers CD, Ezzati M, Jamison DT, Murray CJ. Global and regional burden of disease and risk factors, 2001: systematic analysis of population health data. Lancet 2006; 367: 1747-57.

4 Albuquerque EX, Pereira EF, Alkondon M, Rogers SW. Mammalian nicotinic acetylcholine receptors: from structure to function. Physiol Rev 2009; 89: 73-120.

5 Millar NS, Gotti C. Diversity of vertebrate nicotinic acetylcholine receptors. Neuropharmacology 2009; 56: 237-46.

6 Rose JE. Multiple brain pathways and receptors underlying tobacco addiction. Biochem Pharmacol 2007; 74: 1263-70.

7 Brunzell DH, Picciotto MR. Molecular mechanisms underlying the motivational effects of nicotine. Nebr Symp Motiv 2009; 55: 17-30.

8 Steinlein OK, Bertrand D. Neuronal nicotinic acetylcholine receptors: from the genetic analysis to neurological diseases. Biochem Pharmacol 2008; 76: 1175-83.

9 Lindstrom J, Anand R, Gerzanich V, Peng X, Wang F, Wells G. Structure and function of neuronal nicotinic acetylcholine receptors. Prog Brain Res 1996; 109: 125-37.

10 Wells GB. Structural answers and persistent questions about how nicotinic receptors work. Front Biosci 2008; 13: 5479-510.

11 Bocquet N, Nury H, Baaden M, Le Poupon C, Changeux JP, Delarue $\mathrm{M}$, et al. X-ray structure of a pentameric ligand-gated ion channel in an apparently open conformation. Nature 2009; 457: 111-4.

12 Zouridakis M, Zisimopoulou P, Poulas K, Tzartos SJ. Recent advances in understanding the structure of nicotinic acetylcholine receptors. IUBMB Life 2009; 61: 407-23.

13 Rose JE. New findings on nicotine addiction and treatment. Nebr Symp Motiv 2009; 55: 131-41.

14 Brody AL, Mandelkern MA, Costello MR, Abrams AL, Scheibal D, Farahi J, et al. Brain nicotinic acetylcholine receptor occupancy: effect of smoking a denicotinized cigarette. Int J Neuropsychopharmacol 2009; 12: 305-16.

15 Dani JA, Ji D, Zhou FM. Synaptic plasticity and nicotine addiction. Neuron 2001; 31: 349-52. 
16 Pidoplichko VI, Noguchi J, Areola OO, Liang Y, Peterson J, Zhang $\mathrm{T}$, et al. Nicotinic cholinergic synaptic mechanisms in the ventral tegmental area contribute to nicotine addiction. Learn Mem 2004; 11: 60-9.

17 Placzek AN, Dani JA. Synaptic plasticity within midbrain dopamine centers contributes to nicotine addiction. Nebr Symp Motiv 2009; 55: 5-15.

18 Picciotto MR, Zoli M, Rimondini R, Lena C, Marubio LM, Pich $\mathrm{EM}$, et al. Acetylcholine receptors containing the beta2 subunit are involved in the reinforcing properties of nicotine. Nature 1998; 391: 173-7.

19 Picciotto MR, Addy NA, Mineur YS, Brunzell DH. It is not "either/ or": activation and desensitization of nicotinic acetylcholine receptors both contribute to behaviors related to nicotine addiction and mood. Prog Neurobiol 2008; 84: 329-42.

20 Gutkin BS, Dehaene S, Changeux JP. A neurocomputational hypothesis for nicotine addiction. Proc Natl Acad Sci USA 2006; 103: $1106-11$.

21 Ahmed SH, Bobashev G, Gutkin BS. The simulation of addiction: pharmacological and neurocomputational models of drug selfadministration. Drug Alcohol Depend 2007; 90: 304-11.

22 Stiefel KM, Gutkin BS, Sejnowski TJ. The effects of cholinergic neuromodulation on neuronal phase-response curves of modeled cortical neurons. J Comput Neurosci 2009; 26: 289-301. 